\title{
THE EARLY PIONEERS OF GLOBAL SOFT CONTACT LENS DEVELOPMENT
}

\author{
Nicholas Grant, BSc \\ Pacific University College of Optometry, \\ Forest Grove, Oregon \\ gran5174@pacificu.edu \\ Mari Fujimoto, O.D. \\ Assistant Professor, Pacific University \\ College of Optometry, Forest Grove, \\ Oregon \\ marifujimoto@pacificu.edu
}

10.14434/hindsight.v52i3.33501

\author{
Patrick Caroline, COT \\ Associate Professor, Pacific University \\ College of Optometry, Forest Grove, \\ Oregon \\ Co-curator The Contact Lens Museum \\ carolinp@pacificu.edu \\ Craig Norman \\ Adjunct Clinical Faculty, Michigan College \\ of Optometry, Big Rapids, Michigan \\ Co-curator The Contact Lens Museum \\ craignorman@ferris.edu
}

\section{ABSTRACT}

This article outlines the history and development of the first hydrophilic biocompatible plastic, called PHEMA. The story traces the notable leaders in its development and provides a timeline from the initial discovery of the hydrogel material to its evolution into the modern soft contact lens.

\section{KEYWORDS}

Otto Wichterle; Drahoslav Lim; Robert Morrison; Allan Isen; Martin Pollak; National Patent Development Corporation; HEMA

\section{INTRODUCTION}

The origin of soft contact lenses is well documented and agreed upon as beginning with Otto Wichterle and Drahoslav Lim and their groundbreaking discovery of the plastic, polyhydroxyethyl methacrylate (PHEMA), in Czechoslovakia during the early 1950s. As with all history, soft contact lens development did not escape the political, social and economic happenings of its time and is intertwined with the major events following the end of World War II and transition to the Cold War era in central Europe. Despite many hurdles that had to be overcome, Drs. Wichterle and Lim are responsible for changing the entire landscape of the contact lens industry in the latter half of the 20th century with their revolutionary discovery.

\section{OTTO WICHTERLE}

Otto Wichterle was born in Prostejov, in central Czechoslovakia on Oct. 27, 1913, into a well-to-do, industrial family. Like his grandfather and father, Otto was supposed to take over the family business related to the manufacturing of farm equipment and motor vehicles; however, his interests were always more focused in the field of science. ${ }^{2}$ In 1936, Otto graduated from the Czech Technical University in Prague, and in 1938 he married his life-long companion Linda. Linda Wichterle would later play a major role in the production of the first soft contact lenses.

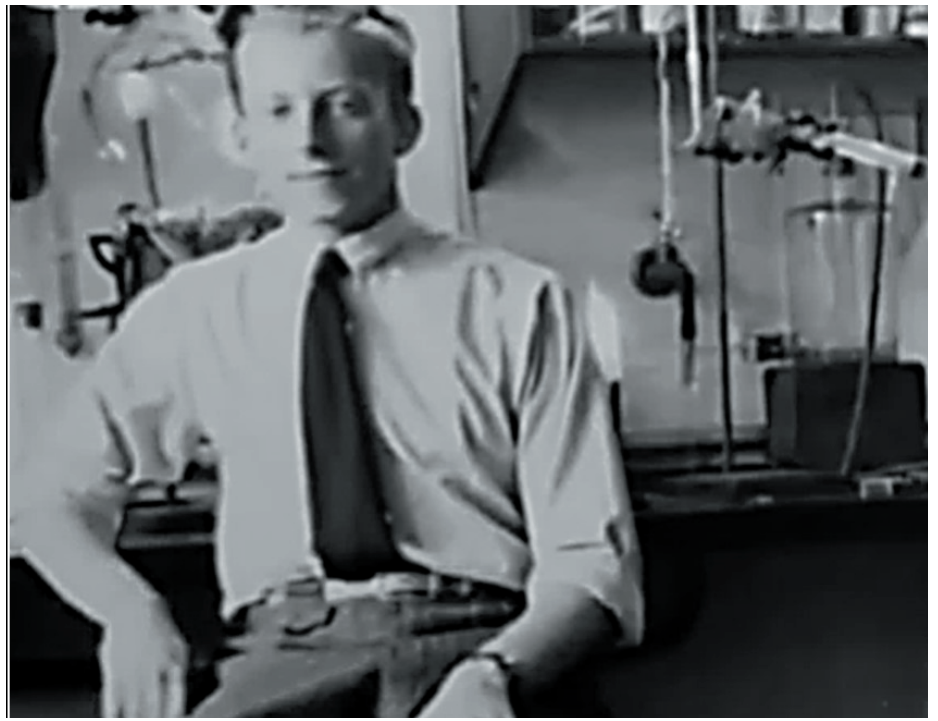

A young Otto Wichterle. (Image courtesy the Wichterle family)

In 1939, Otto Wichterle earned the first of his two doctorates in chemistry; however, his professional career was quickly halted with the dawn of World War II and the German invasion of Czechoslovakia. ${ }^{3}$ Under German rule, the universities were closed 
and students and professors at higher-educational institutes were often arrested and placed into concentration camps. In 1940, Wichterle was able to escape this fate by finding employment in the chemical research department at Bat'a Shoe Company in Zlin, Czechoslovakia.

It was during this period that Wichterle contributed to the development of Silon, a similar material to nylon for synthetic socks and tights.' In 1942, the often-outspoken Wichterle was imprisoned by the Gestapo and held for five months, though it is unclear as to why he was arrested. ${ }^{3}$ It is rumored that a top German chemist was familiar with Otto's work and contributed to his eventual release.

At the end of the war in 1945, Wichterle started work on his second doctorate in organic chemistry at the University of Prague, where he became a professor within the department of plastics. ${ }^{2}$ His interest in the chemistry of plastics had impeccable timing, as the age of plastics in the 1950s was about to begin.

\section{DRAHOLSLAV LIM}

Born Sept. 30, 1925, Lim was several years younger than Otto Wichterle. Similar to Wichterle, he had a Ph.D. in chemistry, and he and Wichterle were working in the same polymer research department at the University of Prague. Not as much is known about Dr. Lim; however, he would be equally credited with the development of the first hydrogel plastic, the material that would change the contact lens industry forever. ${ }^{2}$ While Dr. Lim contributed significantly to the development of the PHEMA material, his involvement became less prominent as the plastic evolved into soft contact lenses. Later in life, Dr. Lim migrated to the United States to continue work as a chemist. He worked at the University of California on plastics involved in artificial kidneys and at Revlon in their department of research on nail enamel. Lim passed away on Aug. 22, 2003, in San Diego, California.

\section{2 - LET THE STORY BEGIN}

The idea of a hydrophilic biocompatible plastic is said to have originated on a train ride in 1952, when Wichterle happened to be sitting next to Dr. Pur, a Ministry of Health official who was reading a medical journal containing an advertisement on metal prosthetics used in ophthalmology. ${ }^{4}$ A conversation ensued that sparked Wichterle's interest in developing a biocompatible plastic for human tissue replacement.

Dr. Lim was the only colleague of Wichterle's interested in joining him in the research and a short six months later they had successfully synthesized the first hydrophilic plastic known as polyhydroxyethylmethacrylate (PHEMA); and so began what would become Wichterle's lifelong journey.

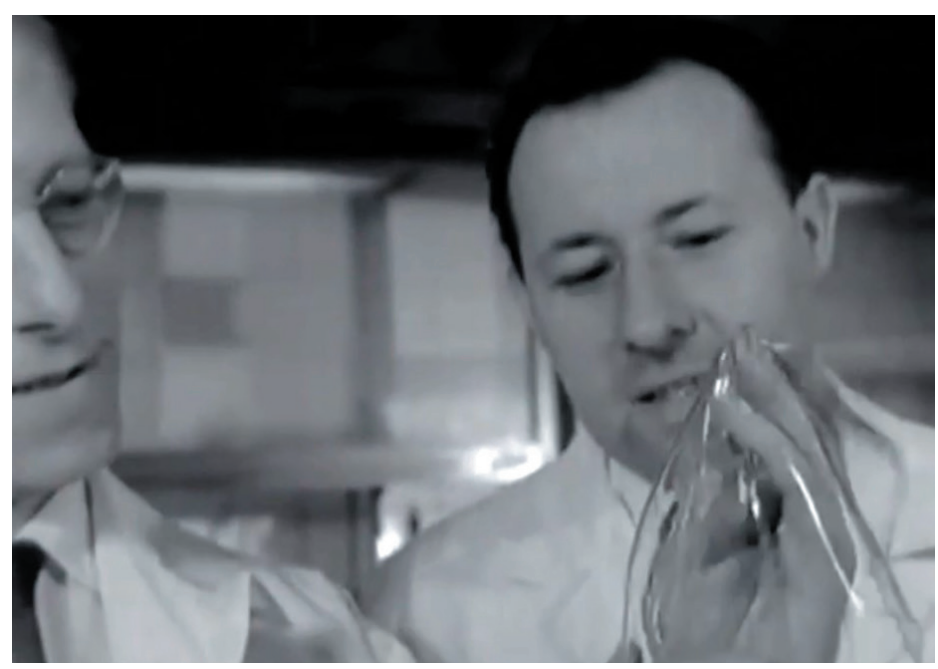

Otto Wichterle (left) with colleague Dr. Drahoslav Lim (right) and their synthesized hydrophilic gel known as polyhydroxyethylmethacrylate (PHEMA), 1955. (Image courtesy the Wichterle family)

\section{3}

Following the development of the PHEMA material, various iterations of the plastic were sent out for toxicology testing. Samples of the materials were implanted into the orbits, sclera and anterior chambers of rabbits, and the gels that were found to be inert were selected.

\section{5}

At this point, the hydrophilic plastic's use, as a contact lens, was not the intended purpose, and Wichterle and Lim immediately applied for several other medical patents. ${ }^{2}$ It was only by chance that the flexible and oxygen-permeable material also turned out to be extremely clear. One of the earliest applications of the HEMA plastic was in an orbital implant surgery in 1955. ${ }^{2}$ Wichterle's son tells us that it was the clarity of the plastic gel that lead Wichterle to be curious as to how this property could be used elsewhere. ${ }^{3}$ Wichterle's idea of creating a soft contact lens was brought forth to the Ministry of Health in Czechoslovakia but, with no interest or support, he was forced to work on the development on his own with willing colleagues and little financial backing. ${ }^{2}$ 


\section{ARTICLE GRANT, FUJIMOTO, CAROLINE \& NORMAN}

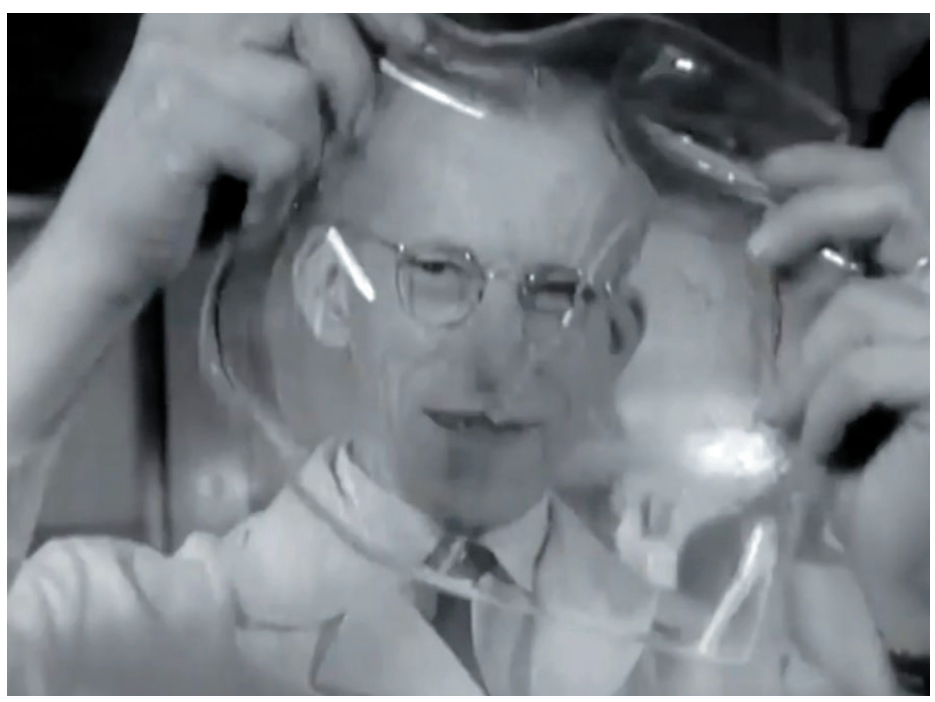

By chance, the hydrogel material was flexible, oxygen permeable and extremely clear. (Image courtesy the Wichterle family)

\section{7}

The majority of contact lenses during this era were full-sized scleral lenses, as corneal lenses were a relatively new innovation. Historically, scleral lenses were manufactured using a molding process to shape the hard plastic (PMMA) and so Wichterle originally attempted to manufacture his water-soluble gel in a similar molding fashion. Unlike its PMMA plastic counterpart, the molded gel material resulted in thick lenses with rough edges. Despite the discomfort one of these lenses would induce, Wichterle is reported to have been the first to apply one of his lens designs onto his own eye in 1957 . $^{2}$

\section{9}

In 1959, Wichterle left the University of Prague and began work as a director at the Institute of Macromolecular Chemistry (IMC). ${ }^{3}$ It was at the IMC that Wichterle and his colleagues were able to create a more optically pure lens by changing their molds from plastic to a glass material. The "rough edges" dilemma was still an issue as these lenses would often stick to the molds upon removal. To minimize the irritation to the eye, each lens was meticulously filed down, creating a tedious process for Wichterle and his colleagues. With about 100 lenses manufactured, it was time for trial on additional eyes. Dr. Maximillian Dreifus of the Second Ophthalmological Clinic in Prague is said to have fit some of the first soft lenses demonstrating only limited success with the prototype lenses. $^{2}$

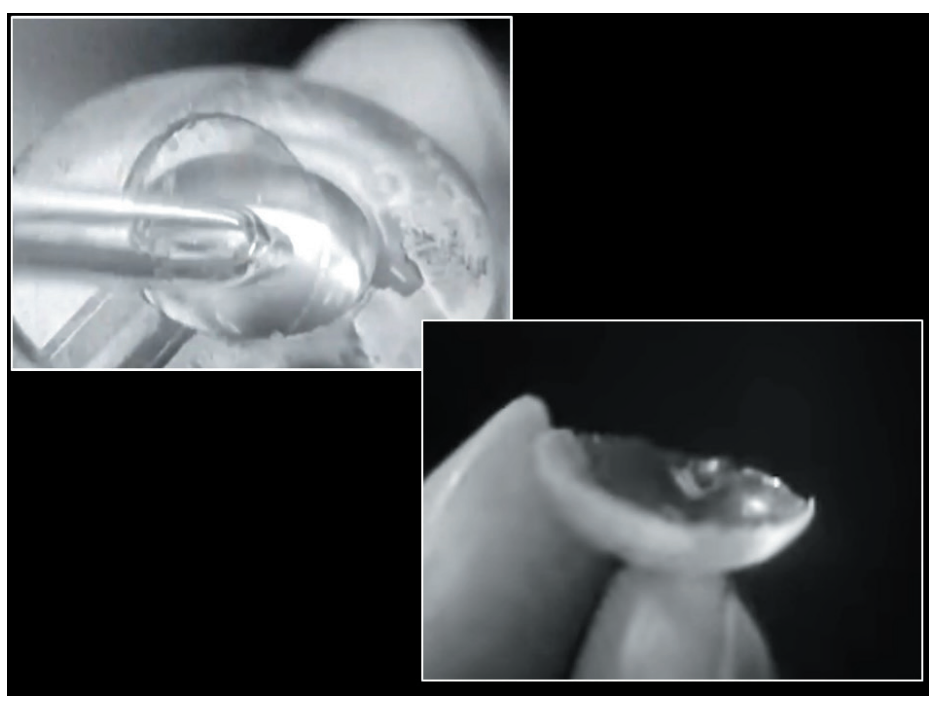

In 1957, Wichterle produced around 100 soft contact lenses from closed polystyrene molds; however, because of contraction of the material during polymerization the edges split and tore as they were removed from the molds. They therefore required hand finishing. (Image courtesy the Wichterle family)

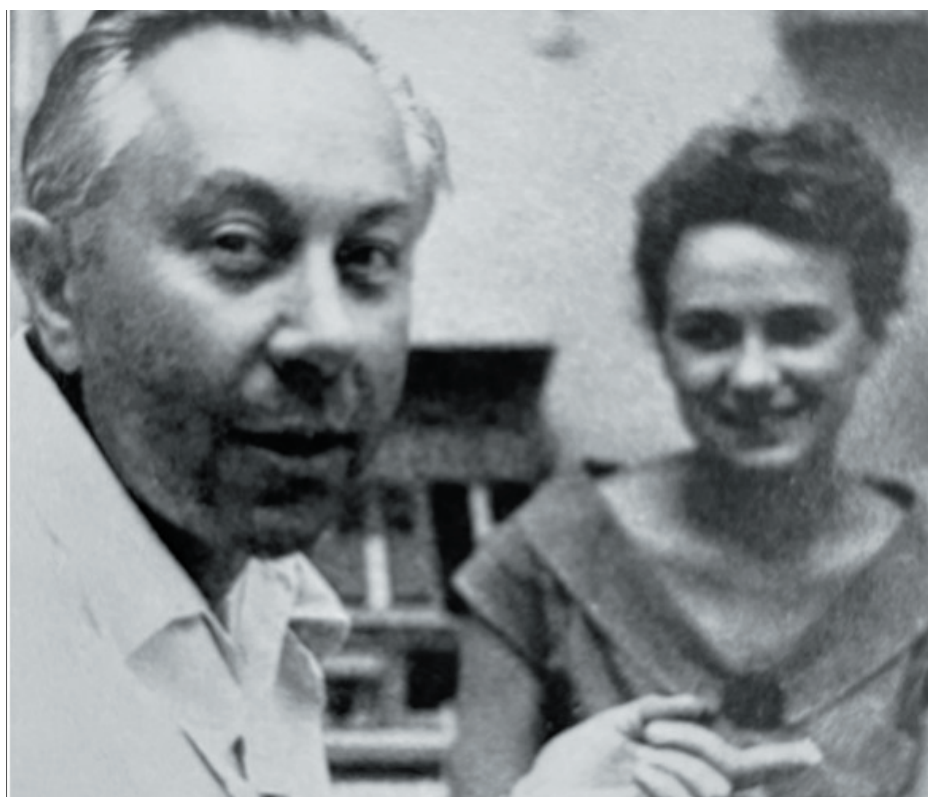

In 1959 Dr. Maximillian Dreifus of the Second Ophthalmological Clinic in Prague fit some of the first soft lenses in practice. (Image courtesy the Wichterle family)

\section{0}

The first published work on the groundbreaking material was published in Nature and authored by Otto Wichterle and Drahoslav Lim. ${ }^{5}$ This article titled, "Hydrophilic Gels for Biological Use" started to gain international attention from investors and companies looking to harness the new technology to their benefit. This article was such a landmark publication that it would be referenced by scientists and clinicians for decades to come. 

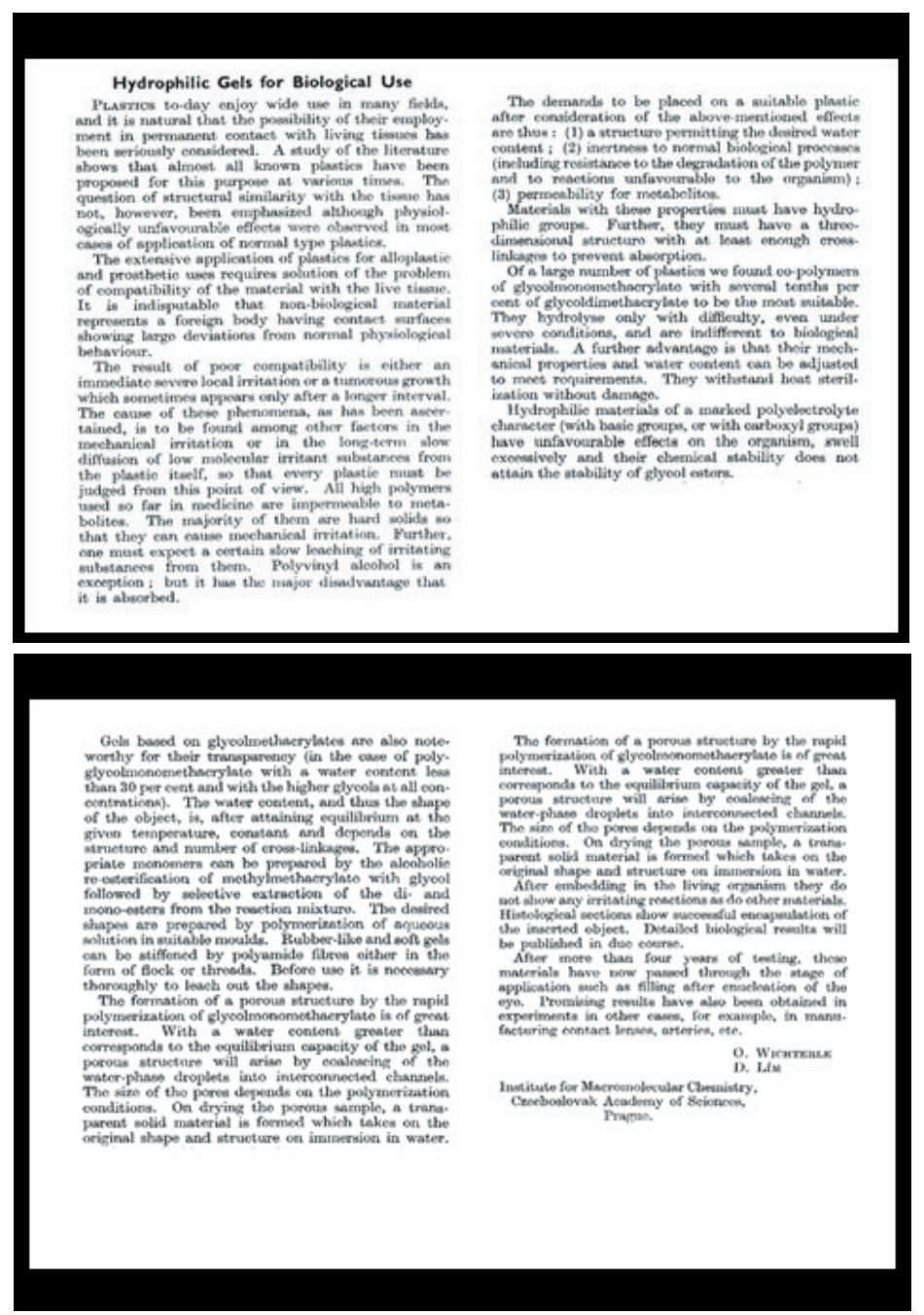

The first paper published on soft contact lenses, "Hydrophilic Gels for Biological Use," by Otto Wichterle, Ph.D., and Drahoslav Lim, Ph.D., Nature, Jan. 8, 1960. (Image courtesy the Wichterle family)

\section{1}

With further budget cuts and reduced funding, the public investigation of hydrogel for the use in contact lenses was ceased. ${ }^{2}$ This forced the passionate Wichterle to continue his research and experiments at home. The primary problem he needed to solve was the issue of lens discomfort. In the early months of 1961, Wichterle conceived the idea of applying a spin-casting method to the manufacturing process. Like many great inventions, inspiration is often drawn from the simplicity in everyday life happenings. Wichterle found his while stirring a cup of coffee! $!^{6,7}$ Being an observant man, he noticed how the edges of the cup formed a capillary interaction with the coffee inside. He imagined this being applied to his contact lenses, and so the spin-casting idea was born. At this point in time, spin casting was reported elsewhere in the world for mirror design. ${ }^{2}$ It was his hope that by having a rotating mold, the lens adherence and edge roughness problem would be solved for the HEMA lenses. With a lack of resources (that Wichterle was accustomed to at his research lab), he had to be innovative in building a machine capable of working the fine gel material into a finished contact lens. He recruited the help of a local glassblower to make the molds as an initial step in putting together a manufacturing process. ${ }^{4}$

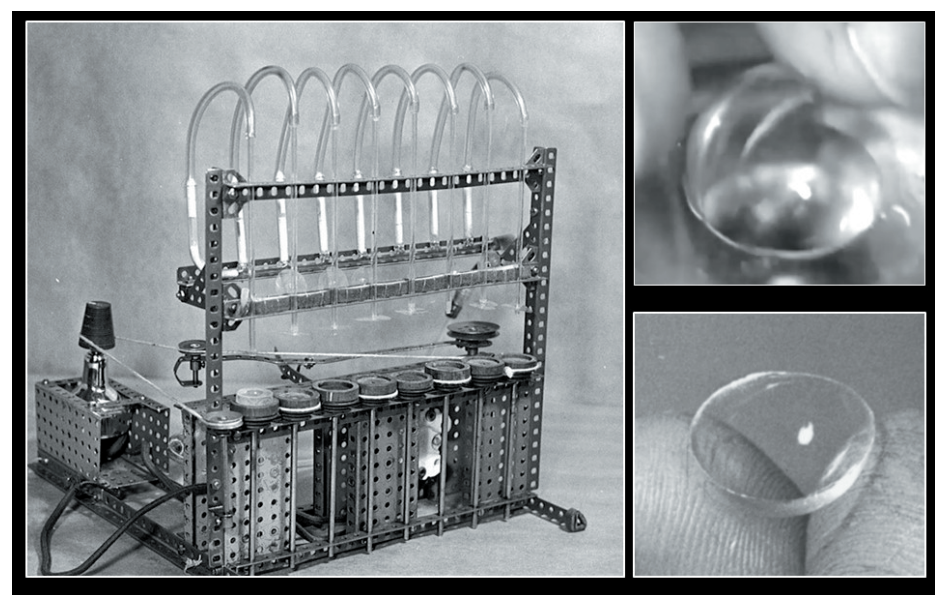

On Christmas Eve 1961, Wichterle built the first spin-cast machine using his son's Merkur (Erector) set and the generator from his bicycle light transformer. On the afternoon of Christmas Day 1961, Wichterle produced the first four usable spin-cast soft lenses on the family's kitchen table. (Image courtesy the Wichterle family)

The following day, Christmas Day 1961, the first four soft contact lenses were produced in the kitchen of the Wichterle household by Wichterle and his family. ${ }^{2,4}$ As one can imagine, Christmas at the Wichterle household in 1961 was not a typical holiday celebration; however, this was a landmark moment in the history of contact lenses and one that would go on to spark a multibillion-dollar industry in the years to come. Wichterle did not waste any time, and the next day the soft lenses were trialed in clinic again at the Second Ophthalmological Clinic by Dr. Dreifus. ${ }^{2}$

\section{2}

As Wichterle's spin-cast soft lens design offered both comfort and optical success, the next goal aimed at increasing the production of these lenses. Adjustments made to the spin-casting machine, such as increasing the number of spindles from four to 15 and adding a more powerful gramophone motor, exponentially increased lens production. ${ }^{2}$ Soft lens manufacturing became a Wichterle family affair, as both his sons, Kamil, Ivan and his wife Linda contributed to the process. Kamil, a trained chemist with mathematical expertise, helped formulate an equation to determine an appropriate spindle rotation speed and the amount of material required for production. ${ }^{4}$ With the help of his wife, an estimated 5,500 lenses were manufactured in their home within the first four months of 1962. 


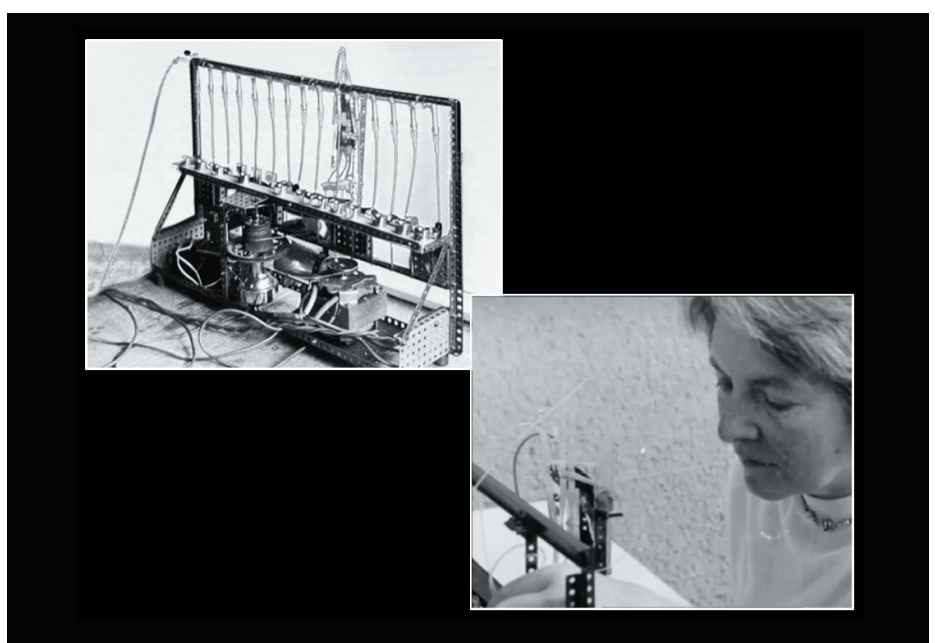

Manufacturing the first spin-cast soft lenses was a family affair, with Wichterle's sons, Kamil and Ivan, formulating the equation to determine spindle rotation speed and the amount of material required, and wife Linda in charge of production. They manufactured an estimated 5,500 lenses in their home within the first four months of 1962. (Image courtesy the Wichterle family)

\section{3}

With great clinical success, funding and support for Wichterle's innovative lenses was finally achieved. Research and development restarted at the Institute of Macromolecular Chemistry in Prague, and a team of about 40 people continued Wichterle's soft lens project. 7 The first soft contacts produced were considered experimental lenses and were known by the name of Geltakt lenses. ${ }^{2}$ Mass production became possible with the installation of three production lines, and the lenses were commercially available in Czechoslovakia under the name SPOFA. ${ }^{2}$ Establishing the soft contact lens as a competitor in the corneal PMMA and an emerging gas permeable lens market proved to be difficult. At this time, it was reported that the technology of a PMMA lens could be worn for up to 14 hours in $75 \%$ of patients while only $10 \%$ of soft contact lens wearers could achieve eight hours. ${ }^{2}$

Being a highly esteemed scientist and researcher, Wichterle joined the International Union of Pure and Applied Chemistry Congress in 1963. ${ }^{2}$ This opportunity afforded him the ability to travel throughout Europe and contributed to the promotion of soft contact lenses in other countries. At a meeting in London, he met several innovators and promoters in the contact lens arena and from them gained new ideas. George Nissel, a contact lens expert in the U.K., suggested that the lenses should be lathe cut similar to hard lenses for more efficient production. ${ }^{2}$ Wichterle was quick to recreate his hydrogel plastic in a dehydrated state and called this material Xerogel. He patented the product in October 1963, and together with previous patents, this gave Wichterle a monopoly on the production of soft lenses for the entire validity period of patents. ${ }^{2}$ As word spread of the radical new soft contact lens, Otto Wichterle continued to play a vital role in the global development of the modality.

The story of how soft lenses became prevalent throughout the world is a complex narrative. Outside of Czechoslovakia, the earliest investigations into the lenses were conducted by Pierre
Rocher at a French contact lens firm called L.O.R. ${ }^{2}$ This company would later become Silor and later become Essilor. It is said that Rocher had read about the new material in the journal, Nature, and decided he needed to see the product for himself. In the summer of 1963, Pierre and his family embarked on a camping trip in Czechoslovakia so that he could see the soft contact lenses in person. ${ }^{2}$ Rocher had a connection with Dr. Driefus through a mutual friend, and in a small, rural Czechoslovakian village he was given a few sample lenses to evaluate. Through Rocher, Silor had one of the first opportunities at what would become a revolutionary product in the contact lens industry. The company at the time was not interested in further investment in the product and so the door remained open for others to investigate. ${ }^{2}$

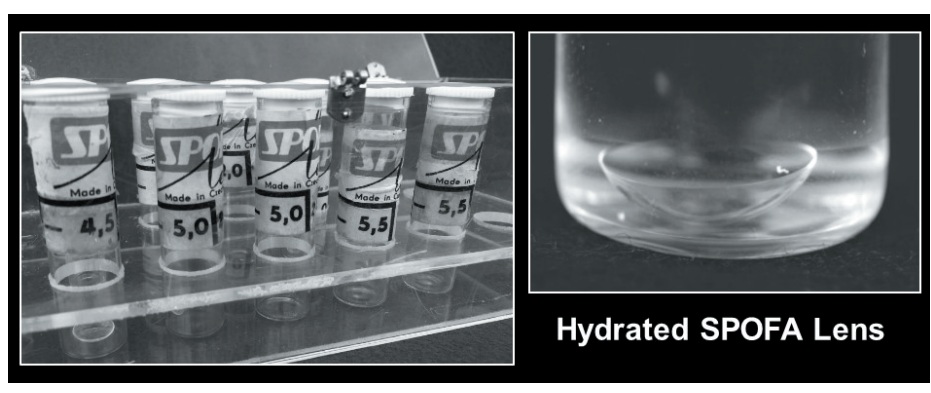

In 1963 the first commercially available soft contact lenses appeared in Czechoslovakia, called SPOFA lenses. (Image courtesy the Contact Lens Museum)

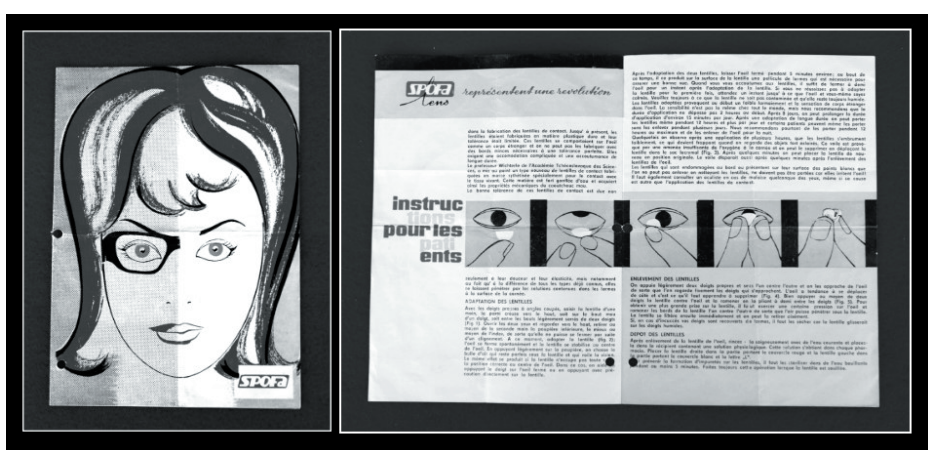

SPOFA Soft Contact Lenses Patient Instruction Booklet (Image courtesy the Contact Lens Museum)

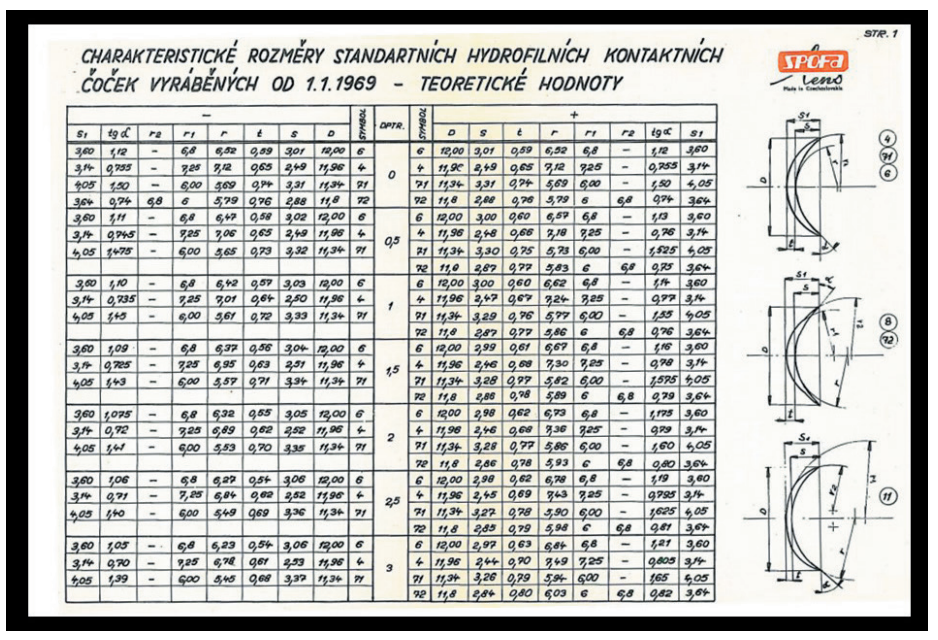

SPOFA Soft Lens Chart (Image courtesy the Contact Lens Museum) Volume 52, Number 3, July 2021 


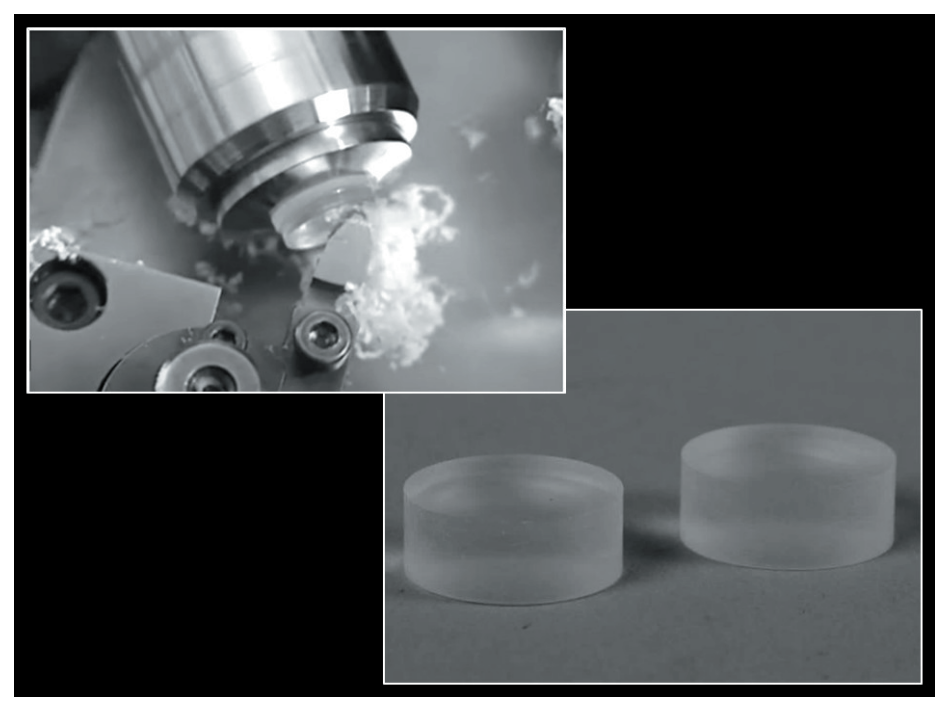

In 1963 Wichterle recreated his hydrogel plastic in a dehydrated state and called this material Xerogel. (Image courtesy the Wichterle family)

\section{4}

In April of 1964, Wichterle presented the world's first lecture on soft contact lenses at a conference organized by his new acquaintance, Pierre Rocher. ${ }^{2}$ This was only the second annual contact lens conference called the Journees d'Etudes de Royaumount hosted in Rocher's home country of France. Later in the year, Wichterle began a tour of America, presenting his research in various U.S. cities. While on his tour it is legend that Wichterle enjoyed boasting about the durability of his lens and the ease of lens cleanliness. According to his wife, the professor claimed the fastest way to clean the lens at the time was to put it in one's mouth. ${ }^{7}$ He often demonstrated this at various events by dropping a lens on the ground, squishing it with his shoe and then proceeding to wet the lens by rinsing it with his saliva and reapplying it to his eye. In contrast to the knowledge we have today about microbiology and sanitization, individuals in 1964 were more fascinated with how robust this lens was during the demonstration. Wichterle's influence began to spread outward from his home country as more people learned about his work. Eventually the news made it to the United States and, in particular, reached an optometrist by the name of Robert Morrison.

Morrison graduated from the Pennsylvania College of Optometry in 1948 and established a contact lens specialty practice in Harrisburg, Pennsylvania, where he quickly gained a reputation as a skilled contact lens clinician. Dr. Morrison expanded his reach providing contact lens fitting for celebrities and patients of royal descent throughout the world. A wellconnected man, Morrison became involved with soft contact lenses through his connection with Pierre Rocher. ${ }^{8}$ When Rocher's company decided not to pursue Wichterle's new lens modality, he was free to pass along the information to colleagues in the field. Morrison later related a phone call he had with Rocher describing the new material and its potential as a contact lens polymer. Intrigued by the new technology, Morrison is reported to have taken a flight to Czechoslovakia the next day in hopes of meeting and learning more from Otto Wichterle. ${ }^{8}$ Morrison worked with Wichterle, and the two men developed a lifelong friendship. Like Rocher, Morrison was given samples of the material to take home. He proceeded to work with the plastic at his own contact lens laboratory, Morrison Laboratories. ${ }^{8}$ In contrast to the spincasting method used in Prague, Morrison began trying to adapt the lathing method that was already an industry standard for manufacturing rigid contact lenses.

Another early suitor for developing soft lenses technology was a company called National Patent Development Corporation (NPDC) based in New York City. The company was founded in 1959 by two attorneys Martin Pollak and Jerome Feldman. ${ }^{2}$ The Wall Street company specialized in purchasing patents that had failed to gain traction in the world market and selling them to interested parties.

At around the same time as when Morrison began working with Wichterle, Martin Pollak was in the USSR exploring different patents for the NPDC. ${ }^{2}$ It was rather unusual for an American company to be conducting business in Russia at this time, especially while the events of the cold war were taking place. Contrary to what one might think, Pollak was treated very well in the communist country as they viewed him as a man of high status because he was one of few Americans still in Russia. Pollak eventually explored other Soviet countries, which lead him to Czechoslovakia and at last to Otto Wichterle. As a businessman, he saw great potential in Wichterle's patents and the monopoly that he had on the new, fascinating area of medical technology. The NPDC believed in the product to such an extent that they were willing to change their business model from acting solely as a company that would transition a product into the hands of someone capable of production to one that wanted to become actively involved in its manufacturing and commercial success.

\section{5}

The rights to the HEMA gel and its production method in the United States were eventually awarded to not just one of the interested parties but both Robert Morrison and the NPDC. ${ }^{2,8}$ Because of the Czechoslovakian political system at the time, Otto Wichterle was only indirectly involved in the deal. The Czech Academy of Science (CAS) was the organization responsible for selling the rights to Morrison and the NPDC, though it is said that Morrison was unaware of any other involved parties until the day the deal was to be signed. ${ }^{8}$ The original agreement was recorded on paper as a transaction between the Czech Academy of Science and a company named Flexible Contact Lens - another blindside to Morrison. ${ }^{2}$ It was on that same day that he found out he was supposedly a 50/50 owner of the company alongside Pollak, Feldman and the NPDC. ${ }^{8}$ In fear of losing out on the soft contact lens opportunity, he reluctantly signed the agreement with the Czech Academy of Science and officially gained rights to the patent for HEMA lens development. Morrison also had Pollak sign an agreement stating his claim in the company to make certain he wasn't being cheated, something that is said to have been written on the inside cover of a torn-out book.

From Otto Wichterle's standpoint, both Robert Morrison and Martin Pollak had their advantages in fulfilling Wichterle's dream of global soft lens development. Morrison was passionate about the science and applicability of a new lens modality. Being an optometrist, he was able to envision how something like HEMA might be able to benefit patients not only medically, but cosmetically as well. Wichterle and the NPDC fit together with a 
shared goal of large-scale expansion and production of the lens. This was something that had significantly limited Wichterle under the communist regime of Czechoslovakia and his power struggle with them for autonomy. The Czech Academy of Science also felt more secure about having two groups working on their invention as the deal that was signed was dependent on contact lens sales and the success of the product. ${ }^{2}$

Another revelation came about when Dr. Morrison found that the stock certificate to the new company included a name besides Martin Pollack and Jerome Feldman's, that of Allan Isen. ${ }^{8}$ Dr. Isen was an optometrist from Buffalo, New York, who graduated from Columbia University in 1950. ${ }^{2}$ His interest in contact lenses commenced shortly after he began the challenging process of fitting monocular aphakes. He started a contact lens laboratory in 1957 called Frontier Contact Lenses and became a prominent name in the contact lens industry. It is reported that Isen was in attendance at the 1964 Indianapolis and New York meetings in which Wichterle had lectured. ${ }^{2}$ Isen even went on to present what he had learned from these lectures at the annual American Academy of Optometry meeting. ${ }^{2}$

\section{6}

After all of the turmoil that occurred with obtaining the rights to Wichterle's patents, Robert Morrison hired a lawyer by the name of James Purcell and filed a lawsuit against the NPDC, Martin Pollack, Jerome Feldman and Allan Isen for $\$ 15$ million each. ${ }^{8}$ They settled outside of court in an agreement to part ways and make payments to Morrison in return for the NPDC having exclusive rights to the license. The settlement was reported to be for a total of $\$ 250,000$, a sum worth millions today taking into account market inflation. Morrison claims that if it wasn't for his signed makeshift deal on the inside of the book cover, he may have never had any rights to the patents at all. ${ }^{8} \mathrm{He}$ also is said to have offered to buy out their share at the time but lost the opportunity on a coin toss. At this time, the NPDC was still a relatively small company in terms of capital and part of the settlement agreement stated that if they missed one payment over the next 5 years, all rights would be forfeited back to Robert Morrison. ${ }^{2,8}$ He was advised by his lawyers that this was a real possibility given the circumstances. However, he would have to wait to find out. Unfortunately for Morrison, the NPDC went elsewhere to cover their financial situation, and in October they brought on Bausch \& Lomb to completely pay off their debt. ${ }^{2}$ This effectively ended Morrison's connection to official licensure of soft contact lens production in America. B\&L in return gained half ownership of the license, and it was at this point that the background work for U.S. production started to commence. ${ }^{2}$ Allan Isen's involvement became more prevalent at this point but was also short lived. With the Bausch \& Lomb agreement, Isen became the head of NPDC's soft lens division. He also consulted for B\&L, but quickly realized he had a distaste for the corporate environment and left to work on his own contact lens laboratory, Griffin Contact Lenses, in Toronto, Canada. ${ }^{2}$

\section{8}

Behind the iron curtain in Czechoslovakia, Otto Wichterle's involvement in scientific innovation became less prominent as he took on a more active role as a spokesperson in a rise against communism. In the past he had been restricted on travel, fired from various university positions and investigated by the secret police for his leftist political affiliations. ${ }^{3}$ In the first half of 1968, liberalization protests had begun, and Wichterle was among 70 highly esteemed Czechoslovakians to sign a document known as the 2,000 Word manifesto. 2,3,7 Wichterle was very outspoken against the Eastern Bloc policies and occupying power in his country. In August of the same year, Warsaw Pact troops and Soviet tanks invaded the country ending the movement known as the Prague Spring. At this time, Wichterle and his family left the country with fears that outspoken individuals similar to Wichterle were going to be executed. ${ }^{7}$ After months of living outside of their country's grasp and no such executions taking place, the Wichterle family returned home. ${ }^{7}$ This was not without consequence, as upon his return, Wichterle was again restricted on travel, speech and work. It is around this time that Otto Wichterle retreated to a life of semiretirement in Czechoslovakia and focused on family life moving forward.

Back in America, Bausch and Lomb continued with their development of the soft contact lens. They voluntarily made an inquiry with the FDA in 1967 as to whether their developed soft lenses would be treated as a medical device and therefore require FDA testing and approval. ${ }^{2}$ Initially, they were informed that they would not be required, and for a brief period in 1968 they began to introduce lenses on an experimental basis to the public. ${ }^{2}$ Henry Knoll, a lead B\&L scientist, reported that 140 patients were fitted in the lens and followed closely., ${ }^{90}$ The protocol at this time included boiling the lens daily for disinfection and regular wear. 9,10 The lens appeared to have enough oxygen permeability as early indications pointed toward good corneal health and few adverse effects. On Dec. 12, 1968, however, the FDA ruled that soft contact lenses would be classified as a drug, which changed the course for soft lens production in the United States and significantly delayed the release of the technology. ${ }^{2}$ Martin Pollack speculated that hard contact lens manufacturers were behind the change in the FDA's decision, but this has never been proven. ${ }^{2}$

Allan Isen at this time had already formed Griffin Laboratories in Canada and began to develop soft lenses outside of the U.S. and away from the NPDC, B\&L and the FDA. Working with a University of Waterloo chemist by the name of Ken O'Driscoll, ${ }^{2}$ they were able to develop a variation of the HEMA plastic, one that was reported to have $57.5 \%$ oxygen transmissibility. ${ }^{11}$ They called the new material Bionite, which would become the basis for their branded soft contact lens, the "Naturalens" or the "Griffin Lens." For Isen, one of the main advantages of the soft, highly permeable lens was its therapeutic use. Like Morrison and others before, Isen produced this lens through a lathe cutting technique due to the greater understanding of this method in the contact lens industry at the time. 


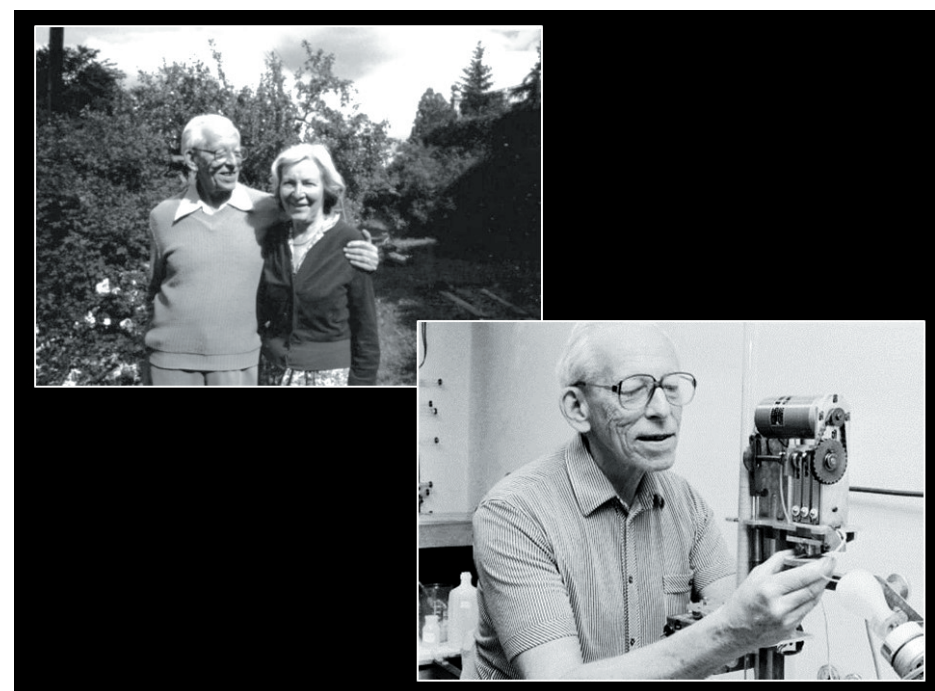

In 1968 the politically outspoken Wichterle was expelled from the Institute of Macromolecular Chemistry and his travel was restricted. It is around this time that Otto Wichterle retreated to a life of semiretirement in Czechoslovakia. (Image courtesy the Wichterle family)

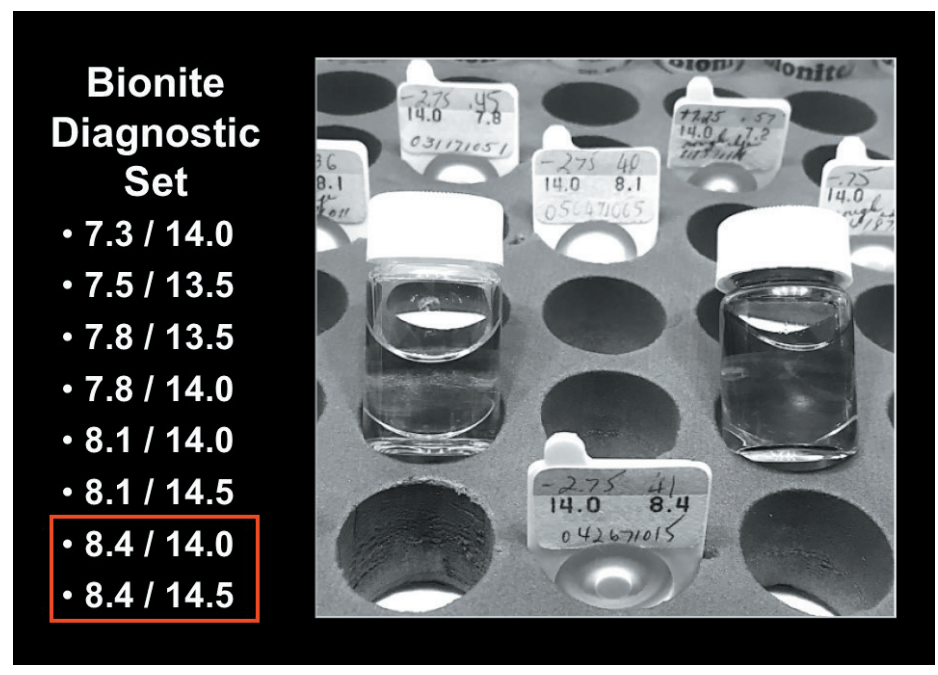

In 1969 Allan Isen formed Griffin Laboratories in Canada and began to develop soft lenses outside of the U.S. and away from the NPDC, B\&L and FDA. They called the new material Bionite, which would become the basis for their branded soft contact lens, the "Naturalens" or the "Griffin Lens." (Image courtesy the Contact Lens Museum)

Spin casting was new and very few people had experience with this process outside of Wichterle and B\&L, who had acquired rights to the patents. During the 1960s, pseudophakic bullous keratopathy was a prevalent complication of cataract extraction, due to a higher risk of damage to the corneal endothelium. Isen's Naturalens was applied as a bandage to the cornea of patients experiencing painful, recurrent corneal erosions and ruptured bullae. The Bionite lens would go on to be one the first HEMA lenses made by lathe cutting that became mass produced for the public. ${ }^{2}$ Later versions of the lens were well known in the market as the Softcon lens.

\section{9-1970}

In Canada, Isen began working with Josh Josephson, O.D., at his contact lens practice in Toronto to fit patients with the new Bionite material. During the late 1960s, the soft lens still had not received FDA approval but word had spread, and Isen's soft lens design became increasingly coveted. American patients in search of an opportunity to be fit in this new contact lens modality flew across the border to see Drs. Isen and Josephsen. It was reported that patients would fly in with Allan Isen on a weekday, and Drs. Isen and Josephson would fit patients late into the night and fly out the next day. Dr. Josephson was an early, soft-lens clinician and made many observations and theories about how to properly fit a soft lens. Unbeknownst to most people, he was the person behind the push for soft lens evaluation. ${ }^{2}$

Bausch and Lomb during this time period was diligently working on their FDA approval, filing an Investigatory New Drug application in April 1969, a second New Drug Application in September of 1969, and another revamped New Drug Application in July of 1970. ${ }^{2}$ Meanwhile, several other contact lens laboratories also began producing lathe cut soft lenses. It is estimated that several hundred companies infringed on the Wichterle patents during this time as "off-label" soft contact lenses began to emerge throughout the world. ${ }^{2}$ Many costly and time-consuming court cases arose in the coming years with the NPDC and Bausch and Lomb attempting to prosecute the many laboratories that wrongfully profited without proper licensure.

\section{1}

On March 18, 1971, Bausch \& Lomb was granted FDA approval to market their "C-Series" Soflens in the United States. The lenses were FDA approved with a daily heat disinfection system that consisted of a modified baby bottle heater and saline made by combining a single salt tablet with non-sterile distilled water.

The $13.5 \mathrm{~mm}$ "C-Series" lenses were manufactured through a modified version of Wichterle's original spin-casting technology in which the base curve radius of the lenses decreased as the anterior surface power increased. Therefore, the base curves of the initial "C-Series lenses were exceptionally steep.

$\begin{array}{cc}\text { “C" Series Power } & \text { Base Curve Radius } \\ -1.00 \mathrm{D} & 8.00 \mathrm{~mm}(42.00 \mathrm{D}) \\ -5.00 \mathrm{D} & 7.45 \mathrm{~mm}(45.25 \mathrm{D}) \\ -10.00 \mathrm{D} & 6.90 \mathrm{~mm}(48.87 \mathrm{D}) \\ -15.00 \mathrm{D} & 6.40 \mathrm{~mm}(52.75 \mathrm{D}) \\ -20.00 \mathrm{D} & 5.95 \mathrm{~mm}(56.50 \mathrm{D})\end{array}$

The B\&L Soflens was initially launched in the Pacific Northwest in 1971, followed by a national rollout that was highlighted by educational symposiums. By Thanksgiving, 1971, they had completed the nationwide launch of the new modality.

The "C Series" fitting set consisted of 72 lenses in a range of different powers. Practitioner cost for each set was $\$ 2,800$ (\$39.00 per lens). Additionally, practitioners had to attend one of the Bausch and Lomb regional training seminars at an additional cost of $\$ 25.00)$ to be certified to fit the new lenses. To put those numbers into perspective today... 
Lens cost: $\$ 39$ per lens in $1971=\$ 252$ per lens today

Trial set cost: $\$ 2,800$ in $1971=\$ 18,079$ today

Typical patient fees: $\$ 300$ in $1971=\$ 1,937$ today

Because the "C-Series" lenses tended to fit steeply on the eye, it was not long before Bausch and Lomb released two additional lenses this time with an overall diameter of $12.5 \mathrm{~mm}$, the "Flatter" fitting F-Series lenses and the "Normal" fitting N-Series lenses.

\section{-2.00 D., 12.5 mm F-Series Base Curve Radius = 8.35 mm}

-2.00 D., $12.5 \mathrm{~mm}$ N-Series Base Curve Radius $=7.80 \mathrm{~mm}$

This was quickly followed by two additional lenses, one the even flatter B-Series lenses and the steeper J-Series lens to fill the gap between the $\mathrm{F}$ and $\mathrm{N}$ Series lenses.

\section{-2.00 D., 12.5 mm B-Series Base Curve Radius $=8.70 \mathrm{~mm}$}

-2.00 D., $12.5 \mathrm{~mm}$ J-Series Base Curve Radius $=8.10 \mathrm{~mm}$

To aid practitioners with the initial lens selection, in 1974, Bausch and Lomb introduced the Best-Fit Band Chart describing the appropriate lens selection for the $12.5 \mathrm{~mm} \mathrm{B,F,J} \mathrm{and} \mathrm{N} \mathrm{series}$ lenses.

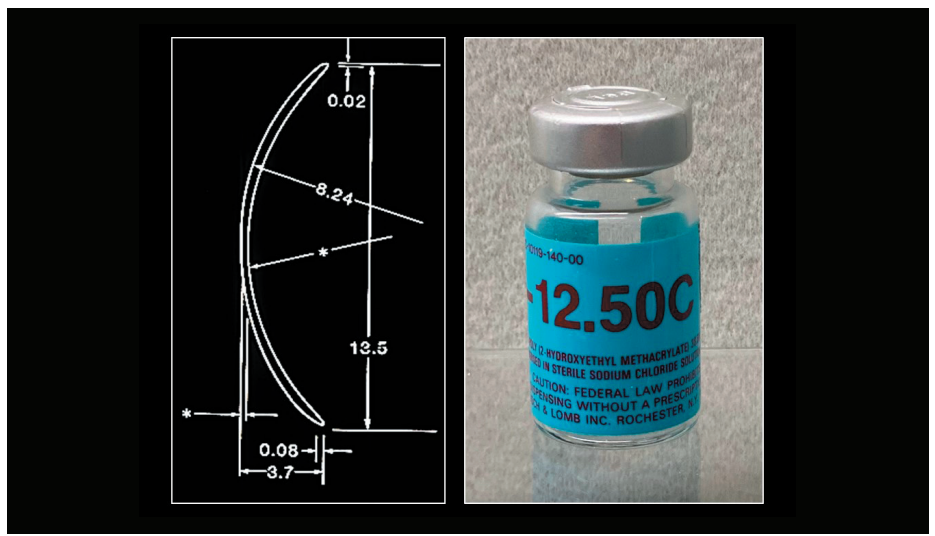

On March 18, 1971 Bausch \& Lomb was granted FDA approval to market the Bausch and Lomb Soflens. The B \& L " $C$ " Series was the first hydrogel lens approved by the FDA for the U.S. market. (Image courtesy the Contact Lens Museum)

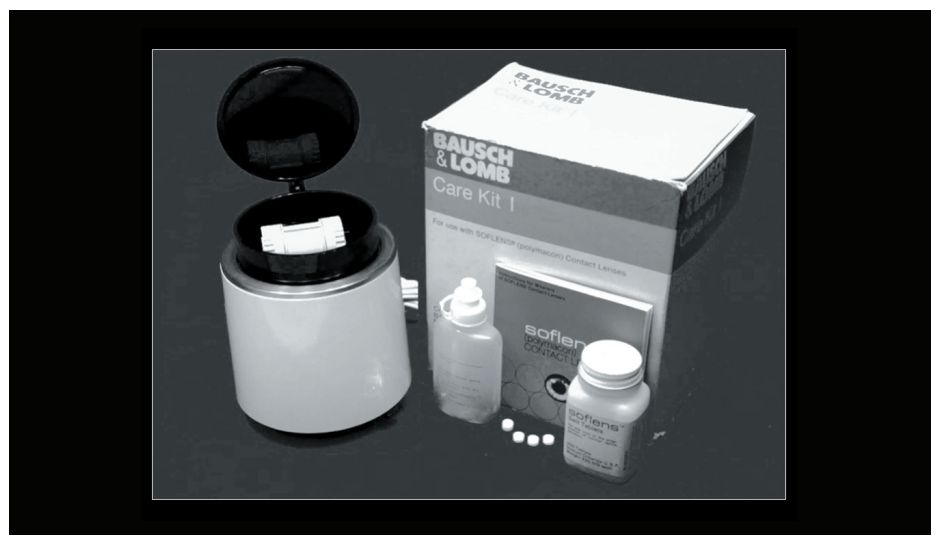

The "C-Series" lenses were FDA approved with daily heat disinfection that consisted of a modified baby bottle heater and saline made by combining one salt tablet with non-sterile distilled water. (Image courtesy the Contact Lens Museum)

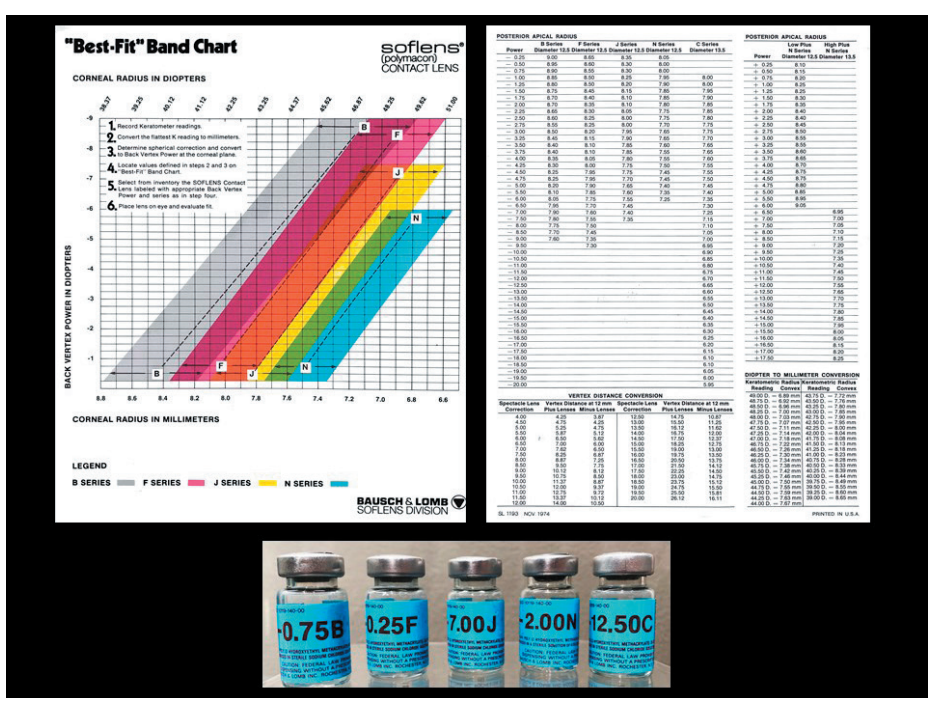

In 1974 Bausch and Lomb introduced the Best-Fit Band Chart. (Image courtesy the Contact Lens Museum)

\section{WICHTERLE RECOGNITION}

Due to Wichterle's political affiliations and his work being mostly conducted under a communist regime, he did not receive proper recognition for his contribution to the contact lens world until decades after completing his innovative work. In a capitalist country he may have been a very wealthy individual; however, this was not the case in Czechoslovakia. The income laws at the time were amended to reduce his income so that he would not receive more pay than high-ranking political officials.? The licensing deal that had occurred with his soft contact lens designs was considered one of the most profitable transactions in the country for a long time. However, recognition finally came to Otto Wichterle after Czechoslovakia transitioned away from its socialist ideologies.

In all, Otto Wichterle:

- wrote six textbooks

- had over 100 scientific publications

- held over 180 patents

- was appointed as president of the Czech Academy of Science in 1990

- $\quad$ had an asteroid (\#3899) named after him in 1993

- was honored with a statue erected outside the Institute of Macro-Molecular chemistry in 2005

- was honored in 2013 by the Czechoslovakian government on the 100th anniversary of his birth with the issue of a commemorative currency

- was honored by the issuing of a commemorative Czechoslovakian stamp on Oct. 16, 2013.

There is no doubt that Wichterle was fundamental in the innovation and development of soft contact lenses. On Aug. 18, 1998, he passed away in his home country and forever remains a legend in the history of contact lenses. 


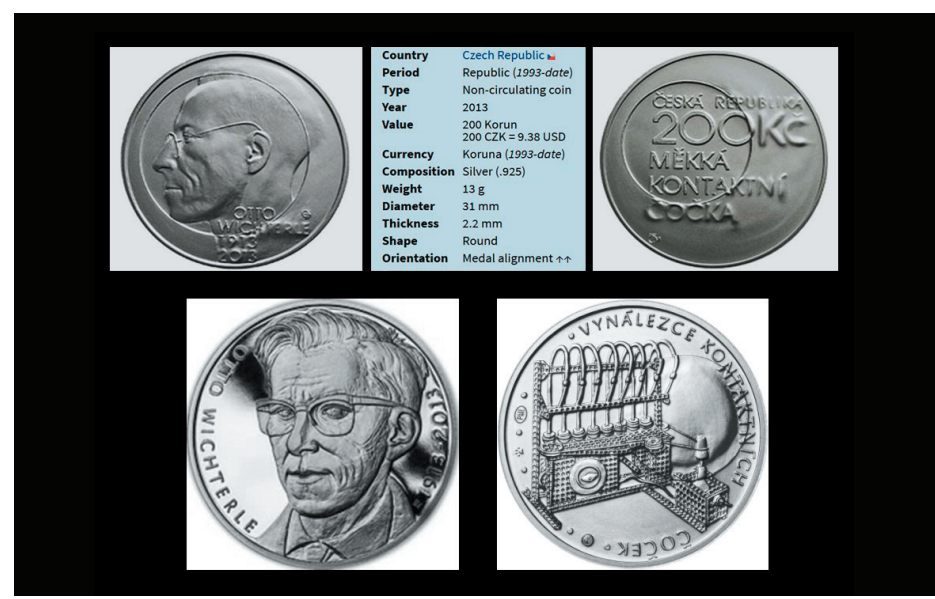

Czechoslovakian commemorative currency issued at the 100th Anniversary of the Birth of Inventor and Chemist Otto Wichterle. (Image courtesy the Contact Lens Museum)

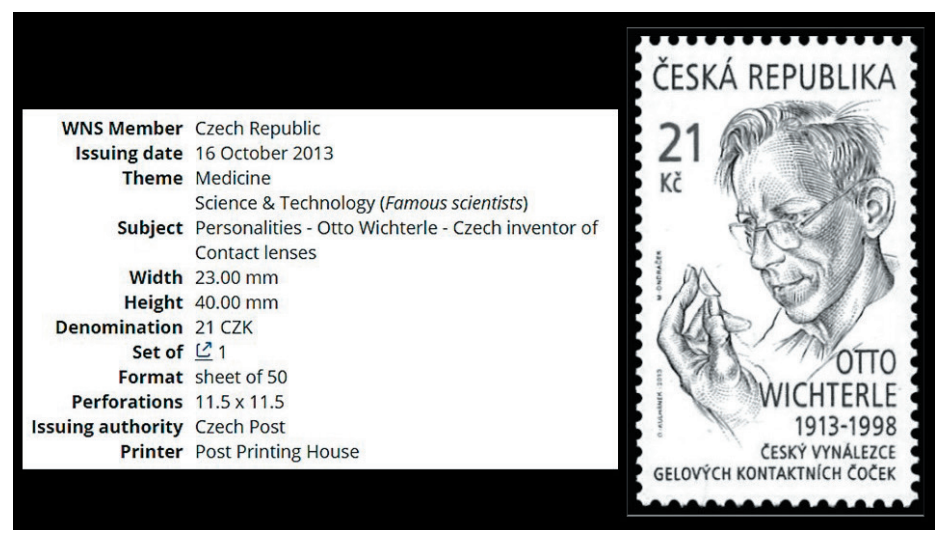

Czechoslovakian Stamp issued Oct. 16, 2013 commemorating Otto Wichterle's birth in 1913. (Image courtesy the Contact Lens Museum)

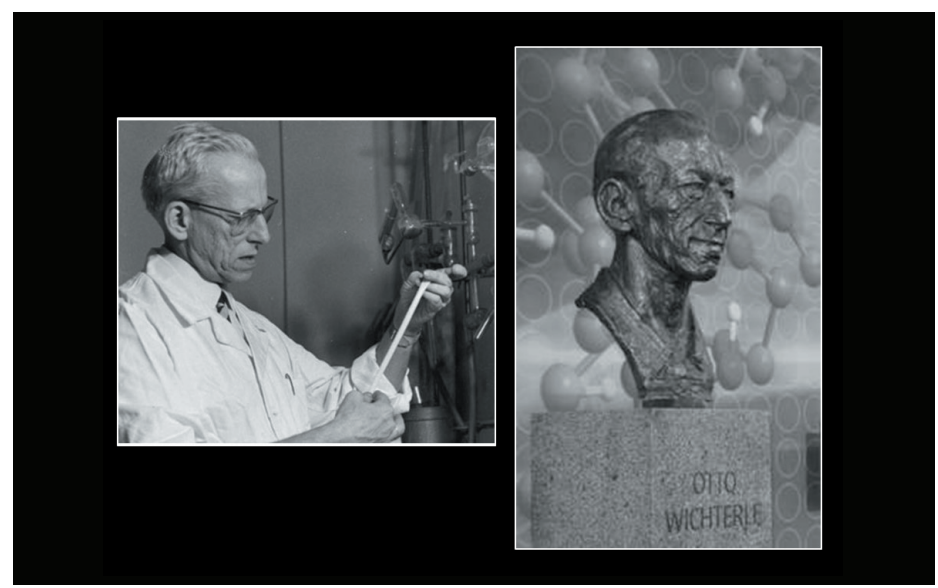

Otto Wichterle passed away on Aug. 18, 1998 at the age of 84. (Image courtesy the Wichterle family)

\section{ACKNOWLEDGMENTS}

The authors would like to acknowledge Tim Bowden for his meticulous research and dedication to the field. His devotion and involvement in recording the history of contact lenses was unparalleled and serves as a pillar for the knowledge we have today.

\section{REFERENCES}

1. Philatelicdatabase.com [Internet]. Stamps of the Czech Republic: Otto Wichterle, Inventor of Contact Lenses (2013). Thematics. 2013 Nov 22 [cited 2020 Aug 31]. Available from: http://www.philatelicdatabase.com/topicals-thematics/ stamps-of-the-czech-republic-inventor-of-contactlenses-2013/.

2. Bowden TJ. Contact Lenses: The Story. United Kingdom: Bower House Publications, 2009: 247-358.

3. Sciencehistory.org [Internet]. Politically Unreliable: The State v. Otto Wichterle. People. 2014 Oct 2 [cited 2020 Aug 31]. Available from: https://www.sciencehistory. org/distillations/politically-unreliable-the-state-votto-wichterle\#: :text=The\%20State\%20v.-,Otto\%20 Wichterle,he\%20nor\%20his\%20country\%20benefited.

4. Thecontactlensmuseum.org [Online Video]. Forget the Frames: Otto Wichterle Story. Otto Wichterle. 2020 [cited 2020 Aug 31]. Available from: https://www.thecontactlensmuseum. org/otto-wichterle.html.

5. Wichterle O, Lim D. Hydrophilic gels for biological use. Nature 1960; 185:117-118.

6. Thecontactlensmuseum.org [Online Video]. Troublemaking Genius. Otto Wichterle. 2020 [cited 2020 Aug 31]. Available from: https://www.thecontactlensmuseum.org/ottowichterle.html.

7. Thecontactlensmuseum.org [Online Video]. Wichterle (Trampled Project Czech Documentary). Otto Wichterle. 2020 [cited 2020 Aug 31]. Available from: https://www. thecontactlensmuseum.org/otto-wichterle.html.

8. Knorr R, Kremer K. Man of Vision: The Story of Dr. Robert Morrison. Osprey, FL: U. S. Publishing, 2006.

9. Contact lenses anyone can wear. Popular Science Magazine 1969; 194(1):84-87.

10. Hydron: New miracle plastic with a myriad of uses. Popular Science Magazine 1969;194(2):92-95.

11. Josephson JE. A report on the refitting of successful Griffin naturalens wearers with Bausch \& Lomb soflens-tm contact lenses (Polymacon). Am J Optom Arch Am Acad Optom 1973;50:416-422. 